\title{
Spectrum of Imaging Findings in Oriental Cerebral Schistosomiasis and Their Categorization by MRI
}

\author{
Ghimire $\mathbf{P}^{1}, \mathbf{W u} \mathbf{G}^{2}$ \\ ${ }^{1}$ Department of Radiology, Nepalgunj Medical College and Teaching Hospital, Kohalpur, \\ Banke, Nepal \\ ${ }^{2}$ Department of Radiology, Shenzhen University General Hospital and Shenzhen University \\ Clinical Medical Academy, Shenzhen, PR China
}

Received: March 5, 2020

Accepted: April 15, 2020

Published: June 30, 2020

Cite this paper:

Ghimire P, Wu G. Spectrum of Imaging Findings in Oriental Cerebral Schistosomiasis and Their Categorization by MRI. Nepalese Journal of Radiology 2020;10(15):16-26.http://dx.doi.org/10.3126/njr.v10i1.33169

\begin{abstract}
Introduction: To describe the spectrum of imaging findings in oriental cerebral schistosomiasis and characterizing different stages by MRI.
\end{abstract}

Methods: A retrospective review of the clinical and MRI images of twenty nine pathologically proven cases of neuroschistomiasis was performed. Patients with either absence of complete MR examination, previously treated patients were excluded from the study. MRI images were analyzed and lesions were evaluated for the following parameters distribution, size, clusterity, perilesional edema, mass effect, intralesional hemorrhage, necrosis, cystic degeneration, any abnormal enhancements, any atypical features as abscess, vasculitis, infarctions, or focal atrophy and encephalomalacia.

Results: Lesions were only supratentorial in 25 cases, only infratentorial in 3 cases while were both supratentorial and infratentorial in 1 case. Lesions were unilateral in 26 cases. Significant mass effect was noted in 8 cases. All nodular and mass lesions were hyperintense or isointense in T1WI while all but two lesions were hyperintense in T2WI. Lesions were predominantly as clustered nodules (12 cases). All nodules enhanced homogeneously except three that demonstrated ring like enhancement. Masses were demonstrated either homogeneous (2 cases) or heterogeneous in enhancement ( 2 cases). Central linear enhancement was noted in 12 cases, leptomeningeal enhancement in 10 cases while gyral enhancement was noted in 1 case.

Conclusions: Radiological presentation of neuroschistosomiasis varies at different stages of infection as well as among the asymptomatic groups. Recognition of spectrum of presentation has an implied role in the overall management and outcome in cases

Key words: Abscess; Encephalomalacia; Necrosis; Neuroschistosomiasis; Vasculitis

\section{INTRODUCTION}

Schistosomiasis, although one of the neglected diseases is the second most prevalent tropical

Correspondence to: Dr. Guangyao Wu

Department of Radiology

Shenzhen University General Hospital

Shenzhen 518055, PR China

Email address: wuguang2002@163.com disease in the world with estimated 500-600 million people at risk of infection. Although the global prevalence of disease cannot be 
estimated, more than 200 million people in the tropical and sub-tropical countries are infected with 120 million being symptomatic and 20 million having severe clinical disease. $^{1,2}$ Of the three major schistosome species infecting humans, Asian or Oriental schistosomiasis, caused by S.japonicum is the most pathogenetic as well as more difficult to control because of its zoonotic nature. A significant endemic focus lies in China, the Philippines and, to a lesser extent in Indonesia causing significant risk of increased morbidity and mortality in individuals residing or having travelled to these regions.

Neuroschistosomiasis (NS) is the most dreaded complication of Schistosomal infections accounting to about 2-4\% of S.japonicum infections. ${ }^{3}$ There are two main pathways by which schistosomes can cause NS- by egg embolism and worm migration, via either artery or vein system, especially the valveless perivertebral Batson's plexus. ${ }^{4}$ Among the threemajor Schistosomal species, S.japonicum preferentially causes cerebral disease while S.mansoni and S.hematobium causes spinal myeloradiculopathy. ${ }^{5}$ This difference has been attributed to various pathogenetic pathways including the assumption of smaller size of the ova of S. japonicum that cantravel without impedance to the leptomeningeal veins. $^{3,4}$ Neurological complications can occur during all phases of schistosomiasis, including the early post-infective stage, the non-toxaemic (asymptomatic) stage and the chronic phases of the disease (intestinal, hepatointestinal and hepatosplenic). ${ }^{5}$ Clinical symptoms of cerebral schistosomiasis are not specific and can commonly be confused with other infective, vascular as well as neoplastic conditions. Cerebral complications depend on the site of involvement, burden and duration of infection as well as other associated clinical factors. Most common symptoms include headache, visual impairment, delirium, seizures, motor deficits and ataxia. ${ }^{6}$ Cognitive impairment and memory loss have been seen in those individuals who are inflicted with the diseases in childhood.

Magnetic resonance imaging (MRI) has gained importance in the diagnosis, assessment of the disease severity and treatment as well as prediction of clinical outcome in cerebral schistosomiasis. Certain findings as the presence of a central linear enhancement in contrast MR images have been mentioned as a specific finding. ${ }^{7}$ Many studies have mentioned a unique nodular enhancement pattern in cerebral schistosomiasis. ${ }^{7,8}$ These findings though are seen in majority of cases are not the exclusive characteristics of cerebral schistosomiasis. ${ }^{9}$ To our knowledge, not any study in the English literature has attempted to classify the MR findings at different stages of infection. It has been seen that the treatment modalities differ in the varying stages of infection and a radiological recognition is all but pivotal. ${ }^{10}$ It is necessary to be aware of these radiological findings which affects the overall management when an individual hailing from or having history of travel to an endemic region presents with equivocal clinical and radiologic presentations. In this study, we attempt to classify the MR imaging features at different stages of cerebral schistosomiasis and also discuss the magnetic resonance spectroscopy findings in a series of patients.

\section{METHODS}

\section{Patient selection}

A computer based search of medical records from four hospital of Central China was performed to find cases which were diagnosed with cerebral schistosomiasis by S.japonicum. We scrutinized the records and identified the cases which had undergone MRI examinations. Our exclusion criteria was i) absence of complete MRI examinations ii) had previously received medical treatment for any form of Schistosomiasis. Patient with evidence of synchronous extracerebral schistosomiasis were not excluded from the study. Medical records were reviewed for demography, clinical presentation, and presumptive diagnosis, method for confirmation of diagnosis, treatment received and immediate post treatment follow-up. Our 
institutional review boards do not require its approval or patient informed consent for this type of retrospective study.

Imaging technique

All MRI were performed with a 1.5 Tesla unit (Philips Eclipse scanner) with a dedicated head coil using the following sequences in various combinations of at least transverse, coronal and sagittal planes: spin-echo T1weighted, fast spin-echo T2-weighted, fast fluid-attenuated inversion recovery (FLAIR) and contrast enhanced spin-echo T1-weighted. The parameters of these sequences were TR/ $\mathrm{TE}=400 / 12 \mathrm{~ms}$ for T1-weighted imaging, $\mathrm{TR} / \mathrm{TE}=4500 / 105.5 \mathrm{~ms}$ for T2-weighted imaging and a field of view of $240 \mathrm{~mm} \times 240$ $\mathrm{mm}$ with a section thickness of $5 \mathrm{~mm}$. Images were obtained in the axial plane parallel to the inferior border of the genu and splenium of the corpus callosum. Contrast enhanced sagittal, coronal and transverse T1-weighed imaging was obtained after intravenous injection of gadopentetate dimeglumine (Magnevist, Schering, Berlin, Germany) with a dosage of $0.2 \mathrm{mmol} / \mathrm{kg}$ of body weight.

Imaging analysis

Images were accessed at the local PACS workstation by two doctors and reviewed independently by two experienced radiologists who had more than 10 years of experience of neuroimaging. The reading radiologists were blinded to the clinical, previous radiological as well as final pathological diagnosis. The MRI images were analyzed and evaluated for the following parameters; lesions-distribution (site, focality- single or multiple), size of the lesion, clusterity in case of nodules (discrete or clustered), amount of perilesional edema with or without any significant mass effect, presence of intralesional hemorrhage, necrosis, cystic degeneration, any abnormal enhancements, any atypical features as abscess, vasculitis, infarctions, or focal atrophy and encephalomalacia. Final assessment was done on mutual consensus.

\section{RESULTS}

\section{Clinical characteristics:}

There were 23 males and 6 females with age ranging from 13 to 60 years (mean $32.1 \pm$ 9.2 years). The most common symptom was headache present in 17 patients. 12 patients had seizure. Two patients had movement or gait disorders while three patients had visual problems. Short term memory loss was present in one case. One patient was asymptomatic. The mean duration of symptoms was $5.2 \pm$ 5.1 weeks ranging from 1 to 21 weeks. The clinical characteristics of the twenty nine patients are summarized in Table 1.

Table 1. Clinical characteristics of patients with neuroschistosomiasis

\begin{tabular}{|l|c|}
\hline Characteristics & n (\%) \\
\hline Sex (M/F) & $23 / 6$ \\
\hline $\begin{array}{l}\text { Mean age (range) } \\
\text { (years) }\end{array}$ & $32.1(13-60)$ \\
\hline Symptoms and signs & $1(3.4 \%)$ \\
\hline Asymptomatic & $17(58.6 \%)$ \\
\hline $\begin{array}{l}\text { Headache } \pm \text { signs of } \\
\text { raised ICT }\end{array}$ & $3(10.3 \%)$ \\
\hline Visual problems & $2(6.9 \%)$ \\
\hline $\begin{array}{l}\text { Movement disorder/ } \\
\text { gait abnormalities }\end{array}$ & $12(41.4 \%)$ \\
\hline Seizure & $2(6.9 \%)$ \\
\hline Memory loss & $9(31 \%)$ \\
\hline Diagnostic modality & $20(69 \%)$ \\
\hline $\begin{array}{l}\text { Pathological confir- } \\
\text { mation of surgical } \\
\text { specimen }\end{array}$ & $\begin{array}{l}\text { Stool and serological } \\
\text { detection }\end{array}$ \\
\hline \multicolumn{2}{|l|}{} \\
\hline
\end{tabular}

\section{Imaging findings:}

Twenty five cases had lesions only in supratentorial region, 3 lesions were only infratentorial while 1 lesion was in both supra- and infratentorial region. The location of the lesions were frontal lobe 10 cases, parietal lobe 9 cases, temporal lobe 3 cases, occipital lobe 3 cases, cerebellum in 3 cases, fronto-parietal in 5 cases, parietotemporal in 2 cases. All regions of cerebrum and cerebellum were involved in one case. Lesions were unilateral in 26 cases (14 right $\& 12$ left) while bilaterally in 3 cases. Size of 
the lesion ranged from $0.8 \mathrm{~cm}$ to $9.6 \mathrm{~cm}$ (mean, $4.7 \pm 1.9$ ) in maximum diameter. Perilesional edema was seen in all cases. Significant mass effect was seen in 8 cases with one having subfalcine while another having transtentorial herniation. Hydrocephalus was seen in two cases. Multifocality was seen in 9 cases. All nodular and mass lesions were hyperintense or isointense in T1WI while all but two lesions demonstrated increased signal in T2WI.

Only clustered nodules were seen in 12 cases while only discrete nodules were seen in 4 cases. Five cases had both discrete as well as clustered nodules. A nodule with mass was seen in 1 case. 3 cases presented only as mass. One case presented as infarction while miliary nodular presentation was seen in one case. All nodules enhanced homogenously while three lesions demonstrated ring-like enhancements. Two masses enhanced as fluffy homogeneous while another two were heterogeneous with one having fluffy and another ring like enhancement. Central linear enhancement was seen in 12 cases $(41.4 \%$ of cases). Leptomeningeal enhancement was seen in 10 cases $(34.5 \%)$. Gyral enhancement was seen in only one case. Representative imaging findings are illustrated in figure 1-5 and imaging characteristics of the patients are summarized in Table 2.
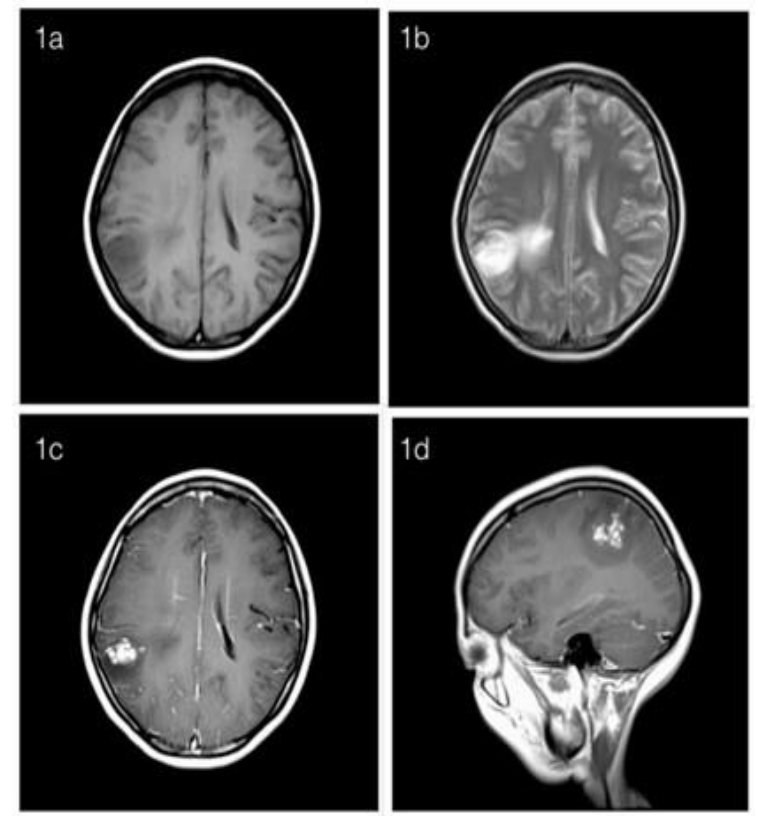

Figure 1. Magnetic resonance imaging (MRI) in a 40-year old man with cerebral schistosomiasis 1a. Axial T1 weighted MR image demonstrates a hypointense lesion in the right parietal lobe with effacement of overlying sulci. $1 \mathrm{~b}$. Axial T2 weighted MR image demonstrates the mass as high signal with surrounding vasogenic edema 1c. Axial T1 weighted MR image with intravenous gadolinium injection shows confluent nodules in the right parietal lobe with surrounding edema. 1d. Sagittal Tl weighted MR image after intravenous contrast demonstrates the characteristic central linear enhancement.
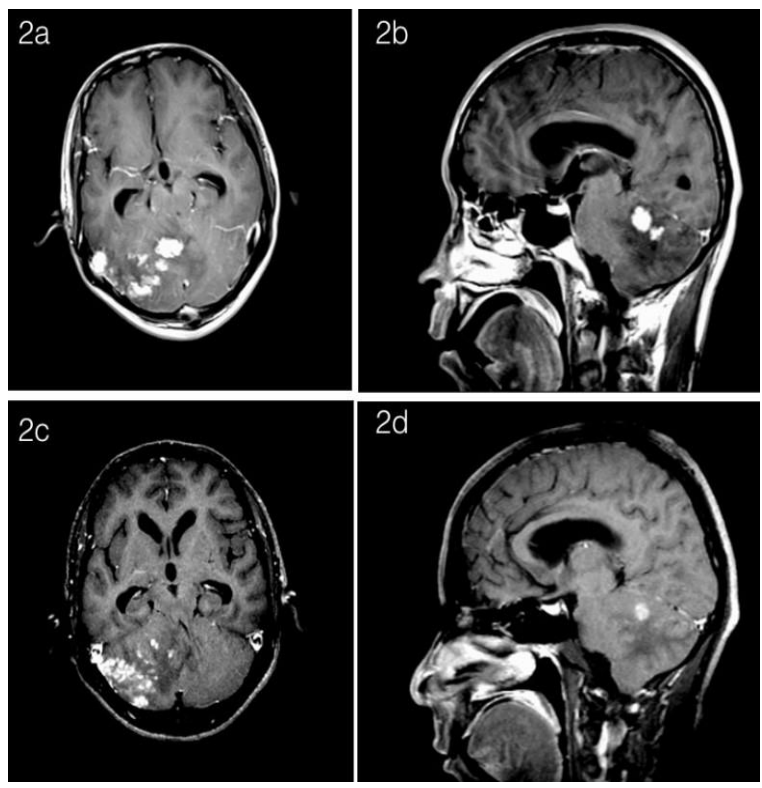

Figure 2. Magnetic resonance imaging (MRI) in a 40 -year old female with cerebral schistosomiasis 2a. Pre-treatment axial T1 weighted MR imagewithcontrastenhancement demonstrates confluent nodules in the right cerebellum with associated leptomeningeal enhancement. Mass effect with effacement of the fourth ventricle and dilatation of the third and temporal horn of lateral ventricles is also noted. $2 \boldsymbol{b}$. Pre-treatment sagittal T1 weighted image demonstrates the confluent nodule and dilatation of the third and lateral ventricles. 2c. Post treatment axial T1 weighted image performed after 6 weeks demonstrates discrete nodules with persistence of the mass effect. 2d. Post treatment sagittal T1 weighted image demonstrates minimal changes compared to the pretreatment MR image findings with patient requiring surgery. 

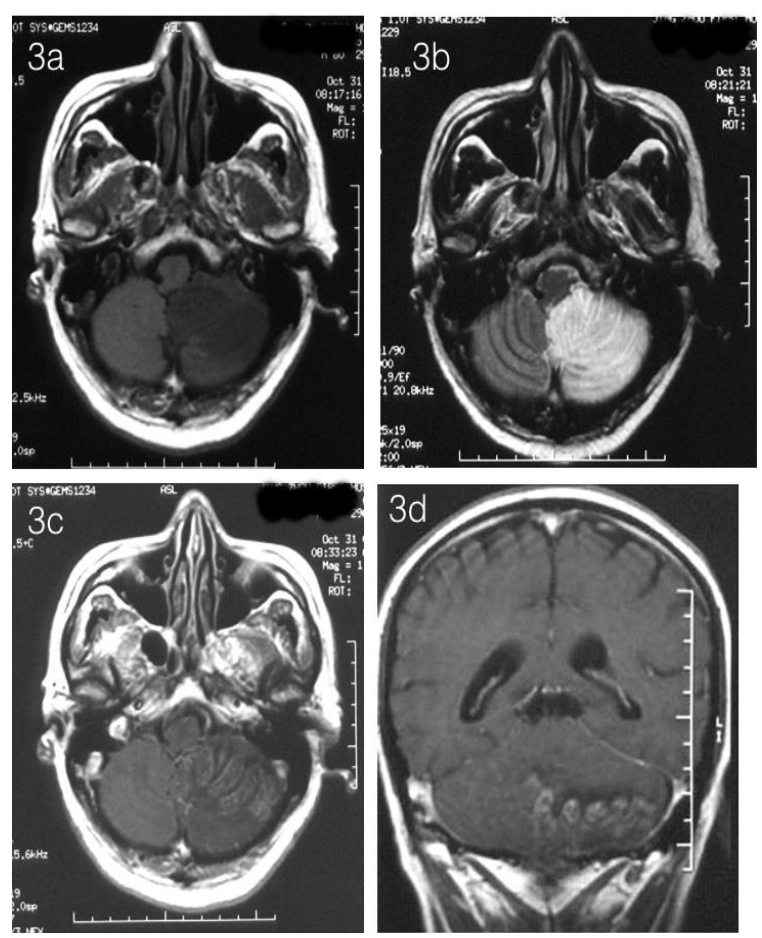

Figure 3. Magnetic resonance imaging (MRI) in a 60-year old man with cerebral schistosomiasis 3a. Axial T1 weighted MR image demonstrates hypointensity in the left cerebellar hemisphere 3 b. Axial T2 weighted $M R$ image demonstrates a well demarcated increased signal in the left cerebellar hemisphere 3c. Axial T1 weighted MR image with intravenous contrast shows cerebellar gyral enhancement pattern 3d. Coronal T1 weighted MR image further also demonstrates dilatation of lateral ventricles.

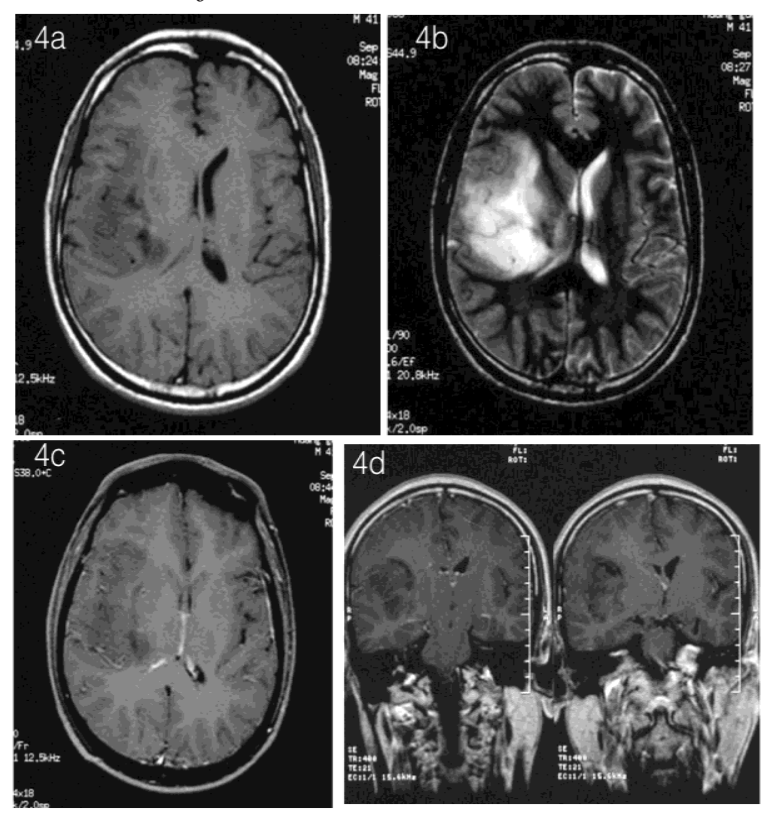

Figure 4. Magnetic resonance imaging (MRI) in a 41-year old man with cerebral schistosomiasis 4a. Axial T1 weighted MR image shows hypointensity in the right parietotemporal region with attenuation of the right frontal and posterior horn of the lateral ventricle 4b. Axial T2 weighted MR image shows hyperintensity at the corresponding region 4c. Axial and 4d. Coronal T1 weighted MR image after contrast administration shows minimal enhancement with marked mass effect.
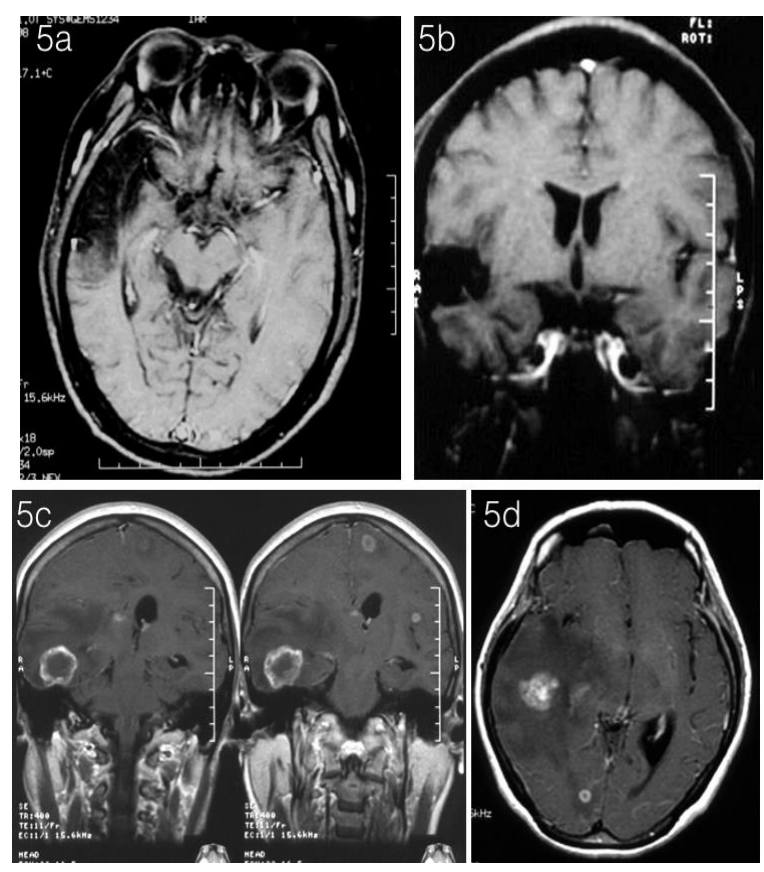

Figure 5. Magnetic resonance imaging (MRI) in a 31-year-old man with chronic cerebral schistosomiasis 4a. Axial and 4b. Coronal T1 weighted image demonstrates atrophy of the right temporal lobe. Magnetic resonance imaging (MRI) in another patient $4 c$. Axial T1 weighted MR image with contrast enhancement demonstrates a confluent nodule, fluffy enhancement and marked edema with mass effect. A ring enhancing lesion is seen in the posterior aspect. $4 \boldsymbol{d}$. Coronal T1 weighted image demonstrates the ring enhancing lesion with an irregular wall on the right side with marked edema and with dilated contralateral ventricle. Multiple small ring enhancing lesions are seen in the left side of the cerebral hemisphere. 
Table 2. MR findings in the cases of neuroschistomiasis

\begin{tabular}{|c|c|c|c|c|c|c|}
\hline Case & Age/Sex & $\begin{array}{l}\text { Lesion } \\
\text { location }\end{array}$ & $\begin{array}{l}\text { Lesions } \\
\text { (n) }\end{array}$ & $\begin{array}{c}\text { Lesion } \\
\text { presentation }\end{array}$ & $\begin{array}{c}\text { Enhancement } \\
\text { patterns }\end{array}$ & $\begin{array}{c}\text { Additional } \\
\text { features }\end{array}$ \\
\hline 1 & $37 / \mathrm{M}$ & $\begin{array}{l}\text { Right fron- } \\
\text { tal lobe, right } \\
\text { fronto-pari- } \\
\text { etal }\end{array}$ & 2 & $\begin{array}{l}\text { Discrete and } \\
\text { c l ust e re d } \\
\text { nodule }\end{array}$ & Homogeneous & $\begin{array}{l}\text { Leptomeningeal } \\
\text { enhancement }\end{array}$ \\
\hline 2 & 38/M & Left frontal & 2 & $\begin{array}{l}\text { Clustere d } \\
\text { nodules, } \\
\text { central linear } \\
\text { enhancement }\end{array}$ & Homogeneous & - \\
\hline 3 & $40 / F$ & $\begin{array}{l}\text { Right cere- } \\
\text { bellum }\end{array}$ & 1 & $\begin{array}{l}\text { Clustere d } \\
\text { nodules }\end{array}$ & Homogeneous & - \\
\hline 4 & $31 / \mathrm{M}$ & $\begin{array}{l}\text { Right parieto- } \\
\text { temporal }\end{array}$ & 1 & Atrophy & - & - \\
\hline 5 & 32/M & $\begin{array}{l}\text { Right fronto- } \\
\text { parietal }\end{array}$ & 1 & $\begin{array}{l}\text { Clustere d } \\
\text { nodules, } \\
\text { central linear } \\
\text { enhancement }\end{array}$ & Homogeneous & - \\
\hline 6 & $60 / \mathrm{M}$ & $\begin{array}{l}\text { Left cerebel- } \\
\text { lum }\end{array}$ & 1 & $\begin{array}{l}\text { Infarction- } \\
\text { left PICA } \\
\text { territory }\end{array}$ & $\begin{array}{l}\text { Gyral en- } \\
\text { hancement }\end{array}$ & $\begin{array}{l}\text { Mass effect on } \\
\text { IV }^{\text {th }} \text { ventricle } \\
\text { with III }{ }^{\text {rd }} \text { and } \\
\text { lateral ventri- } \\
\text { cle ventriculo- } \\
\text { megaly }\end{array}$ \\
\hline 7 & $31 / \mathrm{F}$ & $\begin{array}{l}\text { Left parieto- } \\
\text { temporal }\end{array}$ & 1 & $\begin{array}{l}\text { Discrete and } \\
\text { clustered }\end{array}$ & Homogeneous & - \\
\hline 8 & $28 / \mathrm{M}$ & $\begin{array}{l}\text { Left frontal } \\
\text { convexity }\end{array}$ & 1 & $\begin{array}{l}\text { Clustere d } \\
\text { nodules, } \\
\text { central linear } \\
\text { enhancement }\end{array}$ & Homogeneous & $\begin{array}{l}\text { Leptomenin- } \\
\text { geal enhance- } \\
\text { ment }\end{array}$ \\
\hline 9 & $42 / \mathrm{M}$ & $\begin{array}{l}\text { Left fronto- } \\
\text { parietal }\end{array}$ & 1 & $\begin{array}{l}\text { Clustere d } \\
\text { nodules, } \\
\text { central linear } \\
\text { enhancement }\end{array}$ & Homogeneous & $\begin{array}{l}\text { Mass effect } \\
\text { with subfalcine } \\
\text { herniation }\end{array}$ \\
\hline 10 & 37/M & $\begin{array}{l}\text { Right parie- } \\
\text { to-temporal, } \\
\text { right occipital }\end{array}$ & 2 & $\begin{array}{l}\text { Clustere d } \\
\text { nodules, } \\
\text { central linear } \\
\text { enhancement }\end{array}$ & Homogeneous & $\begin{array}{l}\text { Mass effect } \\
\text { transtentorial } \\
\text { herniation }\end{array}$ \\
\hline 11 & $32 / \mathrm{M}$ & $\begin{array}{l}\text { Right tempo- } \\
\text { ral, left fron- } \\
\text { tal, left pari- } \\
\text { etal }\end{array}$ & 3 & $\begin{array}{l}\text { Mass, } \\
\text { nodules }\end{array}$ & $\begin{array}{l}\text { Ring like, het- } \\
\text { erogeneous }\end{array}$ & - \\
\hline
\end{tabular}




\begin{tabular}{|c|c|c|c|c|c|c|}
\hline 12 & $36 / \mathrm{M}$ & $\begin{array}{l}\text { All lobes in- } \\
\text { cluding cer- } \\
\text { ebellum }\end{array}$ & $>3$ & $\begin{array}{l}\text { Miliary } \\
\text { nodules }\end{array}$ & $\begin{array}{l}\text { Ring like, ho- } \\
\text { mogeneous }\end{array}$ & $\begin{array}{l}\text { Leptomenin- } \\
\text { geal enhance- } \\
\text { ment, mass ef- } \\
\text { fect }\end{array}$ \\
\hline 13 & $37 / \mathrm{M}$ & $\begin{array}{l}\text { Right fronto- } \\
\text { parietal }\end{array}$ & 1 & Mass & $\begin{array}{l}\text { Fluffy, hetero- } \\
\text { geneous }\end{array}$ & Mass effect \\
\hline 14 & 19/M & Right frontal & 1 & $\begin{array}{l}\text { Discrete } \\
\text { nodules }\end{array}$ & Homogeneous & - \\
\hline 15 & $15 / \mathrm{M}$ & $\begin{array}{l}\text { Right cerebel- } \\
\text { lum (vermis) } \\
\text { periventricu- } \\
\operatorname{lar}\left(4^{\text {th }}\right)\end{array}$ & 1 & $\begin{array}{l}\text { Discrete and } \\
\text { c lust e re d } \\
\text { nodules }\end{array}$ & $\begin{array}{l}\text { Fluffy, homo- } \\
\text { geneous }\end{array}$ & $\begin{array}{l}\text { Mass effect } \\
\text { with ventricu- } \\
\text { lomegaly (lat- } \\
\text { eral, III }{ }^{\text {rd }} \text { ven- } \\
\text { tricle) }\end{array}$ \\
\hline 16 & $32 / \mathrm{F}$ & Left temporal & 1 & $\begin{array}{l}\text { Discrete and } \\
\text { c lust e re d } \\
\text { nodule }\end{array}$ & Homogeneous & - \\
\hline 17 & $41 / \mathrm{F}$ & Right Frontal & 1 & $\begin{array}{l}\text { Discrete and } \\
\text { c l ust e re d } \\
\text { nodules }\end{array}$ & Homogeneous & - \\
\hline 18 & 37/M & Left parietal & 2 & $\begin{array}{l}\text { Discrete nod- } \\
\text { ules }\end{array}$ & Homogeneous & $\begin{array}{l}\text { Leptomenin- } \\
\text { geal enhance- } \\
\text { ment }\end{array}$ \\
\hline 19 & 31/M & Left parietal & 1 & Mass & $\begin{array}{l}\text { Fluffy, homo- } \\
\text { geneous }\end{array}$ & - \\
\hline 20 & $35 / \mathrm{M}$ & $\begin{array}{l}\text { Right pari- } \\
\text { etal, left pari- } \\
\text { etal }\end{array}$ & 1 & $\begin{array}{l}\text { Clustere d } \\
\text { nodules, } \\
\text { central linear } \\
\text { enhancement }\end{array}$ & Homogeneous & $\begin{array}{l}\text { Leptomenin- } \\
\text { geal enhance- } \\
\text { ment }\end{array}$ \\
\hline 21 & 19/M & Right frontal & 1 & $\begin{array}{l}\text { Clustere d } \\
\text { nodule, } \\
\text { central linear } \\
\text { enhancement }\end{array}$ & Homogeneous & $\begin{array}{l}\text { Leptomenin- } \\
\text { geal enhance- } \\
\text { ment }\end{array}$ \\
\hline 22 & $32 / \mathrm{F}$ & $\begin{array}{l}\text { Right pari- } \\
\text { etal, right oc- } \\
\text { cipital }\end{array}$ & 2 & $\begin{array}{l}\text { Discrete } \\
\text { nodules }\end{array}$ & Homogeneous & $\begin{array}{l}\text { Leptomenin- } \\
\text { geal enhance- } \\
\text { ment }\end{array}$ \\
\hline 23 & $35 / \mathrm{M}$ & $\begin{array}{l}\text { Right fronto- } \\
\text { parietal }\end{array}$ & 1 & $\begin{array}{l}\text { Clustere d } \\
\text { nodules, } \\
\text { central linear } \\
\text { enhancement }\end{array}$ & Homogeneous & - \\
\hline 24 & $38 / \mathrm{M}$ & Left parietal & 1 & Mass & $\begin{array}{l}\text { Fluffy, homo- } \\
\text { geneous }\end{array}$ & Mass effect \\
\hline
\end{tabular}




\begin{tabular}{|c|c|c|c|c|c|c|}
\hline 25 & $22 / \mathrm{M}$ & $\begin{array}{l}\text { Left frontal, } \\
\text { left parietal }\end{array}$ & 3 & $\begin{array}{l}\text { Discrete and } \\
\text { c l ust e re d } \\
\text { nodules, } \\
\text { central linear } \\
\text { enhancement }\end{array}$ & Homogeneous & $\begin{array}{l}\text { Leptomeningeal } \\
\text { enhancement }\end{array}$ \\
\hline 26 & $28 / \mathrm{M}$ & Left parietal & 2 & $\begin{array}{l}\text { Clustere d } \\
\text { nodules, cen- } \\
\text { tral linear en- } \\
\text { hancement }\end{array}$ & Homogeneous & Mass effect \\
\hline 27 & $13 / \mathrm{M}$ & Right frontal & 1 & $\begin{array}{l}\text { Clustere d } \\
\text { nodules, } \\
\text { central linear } \\
\text { enhancement }\end{array}$ & Homogeneous & $\begin{array}{l}\text { Leptomeningeal } \\
\text { enhancement }\end{array}$ \\
\hline 28 & $35 / \mathrm{M}$ & Left temporal & 2 & $\begin{array}{c}\text { Discrete } \\
\text { nodules }\end{array}$ & Homogeneous & - \\
\hline 29 & $28 / \mathrm{F}$ & $\begin{array}{l}\text { Right frontal, } \\
\text { right fronto- } \\
\text { parietal }\end{array}$ & 2 & $\begin{array}{l}\text { Clustere d } \\
\text { nodule, c } \\
\text { entral linear } \\
\text { enhancement }\end{array}$ & Homogeneous & $\begin{array}{l}\text { Leptomeningeal } \\
\text { enhancement }\end{array}$ \\
\hline
\end{tabular}

\section{DISCUSSION}

Neuroschistosomiasis (NS) is considered the most dreaded complication with an incidence of about $2-4 \%$ of all schistosomal japonicum infections. ${ }^{3}$ Among the most common three species of schistosomiasis, S. japonicum preferentially involves brain while $\mathrm{S}$. mansoni and S.hematobium commonly affect the spinal cord. ${ }^{5}$ There are 2 main pathways by which schistosomes cause NS: egg embolism and worm migration, via either artery or vein system, especially the valveless perivertebral Batson's plexus with a contributory role of portal hypertension with hepatosplenic schistosomiasis. ${ }^{4}$ The adult worm migrates anomalously through the above pathways to the CNS where they lay eggs and incite an immunologic reaction. ${ }^{4}$ The spectrum of immune reaction varies from no or minimal to a very intense reaction, resulting in granulomas or space-occupying mass lesions. Clinical and radiological presentations depend on various factors as pattern of exposure, species of the parasite and disease burden, immune status of the host, duration of infection as well as the age of presentation.

Very few English literatures have discussed the radiological appearance of NS. ${ }^{7,8}$ However, to our knowledge they have not focused on the radiological presentation at different stages of infection as well as among the asymptomatic groups. Recognition of the different stages of infection has an implied role in the overall management and outcome in cases. Based on clinical presentation and radiological appearance, we consider categorization of neuroschistosomiasis into four stages to be prudential in the management of cases. Although majority of cases follow this stage of pathogenesis, several differences do occur that depends on various factors as mentioned above.

The first category is the early vasculitis form with resulting in multiple or border zone infarctions as seen in 2 our patients. ${ }^{11,12}$ The pathophysiological mechanism for this has been attributed to an eosinophilmediated toxicity leading to vasculitis and small vessel thrombosis. ${ }^{10}$ Treatment with antihelminthics at this stage often results in clinical deterioration as evidenced in certain clinical observations. ${ }^{10}$ Vasculitis form of schistosomiasis has to be differentiated from other immune and infective causes of 
vasculitis as polyarteritis nodosa, giant cell (temporal) arteritis, granulomatous arteritis, Takayasu disease (idiopathic aortitis), systemic lupus erythematosus, infectious vasculitis (bacterial endocarditis, pyogenic meningitis, tuberculous meningitis, CNS syphilis, fungal vasculitis). When presenting as infarction, it has to be differentiated further from other etiologies as thromboembolic, hematologic, metabolic disorders, as well as from carcinomatous meningitis and tumors. A relevant clinical history, blood and cerebrospinal fluid (CSF) examination as well as further radiologic investigations usually aid in the diagnosis.

This encephalitis or encephalomyelitis form is evidenced by widespread lesions characteristically in the subcortical and central white matter and cortical gray white matter junction of cerebral hemispheres, cerebellum, brain stem and spinal cord with relatively lesser involvement of periventricular and gray matter of cortex, thalamus and basal ganglia. ${ }^{10}$ This is considered to be mediated by immune complex formed during a systemic hypersensitivity reaction to a newly released eggs as well as adult worms. Lesions may be local or diffusely confluent with variable degrees of edema. Lesions are typically hypointense or isointense on T1-weighted images. T2-weighted images are sensitive and demonstrate asymmetrical foci of hyperintensity with size and number of lesions being variable. On intravenous injection of gadolinium, some of the lesions may exhibit contrast enhancement especially during later stages. As a general rule, lesions subside as the ensuing process diminishes. Encephalitis or encephalomyelitis form can be easily confused with various viral infections, post vaccinal conditions as well as from demyelinating diseases as multiple sclerosis (MS). A clinical history and presentation will often aid towards the diagnosis. MS is relapsing and remitting with optic neuritis more commonly present while schistosomal manifestation is typically a monophasic illness.

Tumoral or granulomatous stage is due to the cell mediated periovular granulomatous reactions resulting in formation of large necrotic-exudative granulomas with surrounding inflammation. With chronicity, the granulomatous response is downmodulated resulting in the productive-stage granulomas which are smaller in size. ${ }^{13}$ Radiologically, this is the stage which has been most extensively reported in the literature.$^{7,8}$ At MRI, findings include a central linear enhancement, surrounded by multiple enhancing punctate nodules measuring 1-2mm in diameter, clustered in a mass like structure with a so called "arborization". Lesions are typically hyperintense on T1-weighted images. On T2-weighted images, the lesions are hyperintense with associated surrounding vasogenic edema and mass effect although a lesion was seen to be hypointense in one of our case. The central linear enhancement pattern has been postulated to be as a result of impeded flow and obstruction caused by anomalous migration of adult worm into the leptomeningeal veins. ${ }^{7}$ In our case series central linear enhancement was noticed in only 12 patients thus making this a specific but not an exclusive MRI finding of NS. Adjacent leptomeningeal enhancement was observed in 10 patients in whom the lesions were cortical. It is believed that certain specific inflammatory components released from the egg results in inflammation of leptomeninges resulting in the enhancement in contrast MR images. Although not proved, a possibility of egg deposition in the leptomeningeal veins itself inciting inflammation can be assumed but with uncertainty. Although, the finding of the unique central linear enhancement is quite specific for cerebral schistosomiasis in the tumoral type, there are certain atypical presentations that poses a diagnostic dilemma. ${ }^{15}$ Mass-like confluent nodules can mimic brain neoplasm as gliomas. Dynamic MR imaging have shown that schistosomal lesions typically are slowly enhancing with confluence of lesions and finally slow washout. Nodular or ring enhancing lesions have to be differentiated from pyogenic infections, tuberculomas, cysticercosis as well as brain tumors. Few studies have focused 
in the magnetic resonance spectroscopy (MRS) findings in neuroschistosomiasis. Increased aspartate, glutathione in addition to the increased Cho/NAA ratio, lactate and lipids has been reported in a study. ${ }^{16}$ In our unpublished study, we found increased $\mathrm{Cho} /$ NAA ratio in all of the cases while lactate and lipids

Resolution or residual stage- With prompt and adequate treatment, granulomas in the healing stage appear smaller in size and often complete resolution in the radiological findings occurs in majority of cases. However, in certain cases, the ensued inflammation resulting in the granulomata will heal with extensive fibrosis, scarring, gliosis leaving behind a recurrent epileptic focus. Mild to moderate degree of cortical and central atrophy have been noted in chronic infections as in one of our case. ${ }^{14}$

Asymptomatic cases are usually considered mild chronic forms and may have minimal radiologic findings including fewer lesions as well as minimal surrounding edema. The lack of symptoms is attributed to the sparse distribution of the eggs and to the scant periovular inflammatory reaction observed in these chronic forms of the schistosomal infection. ${ }^{13}$

No specific guidelines exist for the treatment of cerebral schistosomiasis. ${ }^{17}$ The various modalities of treatment in neuroschistosomiasis include antischistosomal drugs, corticosteroids, antiepileptic's, and surgery. ${ }^{3,18}$ Since majority of cases of neuroschistosomiasis can achieve resolution completely, radiological recognition of not only the disease entity but the stage of infection has an implied value in stratification of treatment on individual basis. ${ }^{17}$ Several studies have shown that in early vasculitis and disseminated encephalomyelitis stage, corticosteroids administration is the only required therapy whereas administration of an antischistosomal drug will further deteriorate the overall condition of the patient. ${ }^{10,19}$ Corticosteroids along with praziquantel however remain the mainstay of treatment in the majority of other cases with dramatic clinical improvement as well as radiologic evidence of resolution. Surgery is usually reserved for cases that i) have equivocal findings in imaging requiring histopathological confirmation ii) massive vasogenic edema leading to mass effect and herniation iii) intracranial hypertension that are not amenable to medical treatment iv) recurrent seizures not responsive to antiepileptics. ${ }^{20}$

\section{CONFLICT OF INTEREST}

None

\section{SOURCES OF FUNDING}

None

\section{REFERENCES}

1. Control of schistosomiasis. Second report of the WHO Expert committee. World Health Organ Tech Rep Ser 1993;830:1-86. Available from: https://apps.who.int/iris/ handle/10665/37115 [Accessed 3rd April 2020].

2. Utzinger $\mathrm{J}$, Raso $\mathrm{G}$, Brooker $\mathrm{S}$ et al. Schistosomiasis and neglected tropical diseases: towards integrated and sustainable control and a word of caution. Parasitology 2009;136(13):1859-74. https://doi. org/10.1017/S0031182009991600

3. Carod-Artal FJ. Neuroschistosomiasis. Expert Rev Anti Infect Ther 2010;8(11):130718. https://doi.org/10.1586/eri.10.111

4. Wang $\mathrm{P}, \mathrm{Wu} \mathrm{MC}$, Chen SJ et al. Research development of the pathogenesis pathways for neuroschistosomiasis. Neurosci Bull 2010;26(2):168-74. https://doi.org/10.1007/ s12264-010-0920-5

5. Carod-Artal FJ. Neurological complications of Schistosoma infection. Trans $R$ Soc Trop Med Hyg 2008;102(2):107-16. https://doi. org/10.1016/j.trstmh.2007.08.004

6. Li Y, Ross AG, Hou X, Lou Z, McManus DP. Oriental schistosomiasis with neurological complications: case report. Ann Clin Microbiol Antimicrob 2011;10(1):5. https:// doi.org/10.1186/1476-0711-10-5

7. Sanelli PC, Lev MH, Gonzalez RG, 
Schaefer PW. Unique linear and nodular MR enhancement pattern in schistosomiasis of the central nervous system: report of three patients. AJR Am J Roentgenol 2001;177(6):1471-4. $\quad$ https://doi. org/10.2214/ajr.177.6.1771471

8. Liu H, Lim CC, Feng $X$ et al. MRI in cerebral schistosomiasis: characteristic nodular enhancement in 33 patients. AJR Am J Roentgenol 2008;191(2):582-8. https://doi. org/10.2214/AJR.07.3139

9. Andrade Filho AS, Queiroz AC, Freire $\mathrm{AC}$ et al. Pseudotumoral form of neuroschistosomiasis: report of three cases. Braz J Infect Dis 2007;11(4):435$8 . \quad$ https://doi.org/10.1590/S1413$\underline{86702007000400014}$

10. Caumes E, Vidailhet M. Acute neuroschistosomiasis: a cerebral vasculitis to treat with corticosteroids not praziquantel. $J$ Travel Med 2010;17(5):359. https://doi. org/10.1111/j.1708-8305.2010.00452 1.x

11. Jaureguiberry S, Ansart S, Perez L, Danis M, Bricaire F, Caumes E. Acute neuroschistosomiasis: two cases associated with cerebral vasculitis. Am J Trop Med Hyg 2007;76(5):964-6. https://doi.org/10.4269/ ajtmh.2007.76.964

12. Houdon L, Flodrops $H$, Rocaboy $M$ et al. Two patients with imported acute neuroschistosomiasis due to Schistosoma mansoni. J Travel Med 2010;17(4):274$7 . \quad$ https://doi.org/10.1111/j.17088305.2010.00401.x

13. Pittella JE. Neuroschistosomiasis. Brain Pathol 1997;7(1):649-62. https://doi. org/10.1111/j.1750-3639.1997.tb01080.x 